\title{
GBEP
}

\section{Consumo da refeição escolar na rede pública municipal de ensino}

Cristiane Herbst Mota

Silmara Salete de Barros Silva Mastroeni

Marco Fabio Mastroeni

\section{Resumo}

O objetivo deste estudo foi verificar a prevalência de alunos que fazem a refeição no domicílio, antes de se deslocarem para a escola, ou que consomem a que é oferecida pela própria escola. Participaram alunos de $1^{\mathrm{a}}$ a $4^{\mathrm{a}}$ série da Rede Pública Municipal de Ensino de Canoinhas-SC. A maioria dos alunos investigados foi do sexo masculino (53,6\%), de escolas da área urbana (63,8\%), e 91,0\% declararam fazer a refeição no domicílio, antes de se deslocar à escola. A maioria $(95,7 \%)$ dos alunos afirmou consumir a refeição oferecida pela escola diariamente no intervalo escolar, mas 77,3\% efetivamente a consumiram. O principal motivo para o não consumo da refeição oferecida pela escola foi o fato de trazerem lanche de casa. Os resultados obtidos foram considerados positivos quando comparados a outros estudos realizados no País. No entanto, outras pesquisas devem ser realizadas, incluindo-se, também, as demais séries do ensino fundamental.

Palavras-chave: alimentação escolar; ensino fundamental; merenda escolar. 


\section{Abstract}

\section{School meal consumption on municipal school}

The aim of this study was to verify the prevalence of students who took the meal at home before going to school, and offered by the school. Study participants were students from $1^{\text {st }}$ to $4^{\text {th }}$ grade of Public Education System of Canoinhas-SC. The majority (53.6\%) of students investigated were male, from urban schools (63.8\%), and 91.0\% reported performing the meal at home before going to school. The majority (95.7\%) of the students reported consuming the meal offered by the school daily during the school break, but $77.3 \%$ had consumed it effectively. The main reason for not eating the meal provided by the school was the fact bringing lunch from home. The results were considered positive when compared to other studies in the country. However, further research should be carried out including also other grades of elementary school.

Keywords: school feeding; elementary school; school meal.

\section{Introdução}

Na última década, as questões relativas à segurança alimentar e nutricional têm sido amplamente discutidas e abordadas em diferentes aspectos: biológicos, sociais, educacionais e econômicos (Oliveira, 2007).

No Brasil, a alimentação escolar é um direito de todos os alunos matriculados nas escolas públicas, no entanto, sua aceitação é variável. Para alguns alunos, principalmente os de condições socioeconômicas menos favorecidas, a alimentação escolar é primordial, pois muitas vezes ele é sua principal ou única refeição do dia. Um estudo realizado pela Universidade Estadual de Campinas (Unicamp) revelou que a alimentação escolar é considerada a principal refeição do dia para 56\% dos alunos da Região Norte e para 50\% dos alunos da Região Nordeste (Sturion et al., 2005).

O número de refeições realizadas ao longo do dia pelos alunos constitui importante indicador do panorama alimentar e do padrão nutricional da criança. Mesmo assim, o consumo da alimentação escolar em alguns municípios brasileiros é considerado baixo, e os motivos relatados pelos alunos são variados. Estima-se que de 15\% a 20\% dos alunos omitam pelo menos uma refeição diária (Sturion et al. 2005).

Apesar deste fato já ter sido observado há décadas, a omissão da refeição na escola ainda é uma realidade no Brasil. Rosenburg (1977), 
já no final da década de 70, havia constatado que 12,6\% das crianças iniciavam suas atividades escolares em completo jejum, apontando para a importância do tema, visto que a alimentação precária pode influenciar no rendimento escolar das crianças (Moysés; Lima, 1983). Pollitt, Gersovitz e Gargiulo (1978) acreditam que as crianças que frequentam a escola sem o café da manhã são provavelmente menos atentas, mais letárgicas e irritáveis.

No Brasil, o Programa Nacional de Alimentação Escolar (Pnae), que atinge mais de 97\% das escolas públicas urbanas e 98\% das rurais existentes no País, tem como objetivo atender às necessidades nutricionais dos alunos e incentivar a prática de hábitos alimentares saudáveis durante sua permanência na escola. Essa atividade contribui para o crescimento, o desenvolvimento, a aprendizagem e o rendimento escolar (Brasil. FNDE, 2006). Mesmo assim, apenas $41 \%$ dos alunos, em média, consomem a refeição escolar diariamente. Nas áreas rurais a aceitação é superior, chegando a 62\%, ao contrário das áreas urbanas, que perfazem 36\% dos alunos. Discrepâncias também têm sido encontradas nas diferentes regiões do Brasil, sendo a média de consumo de 51\% na Região Nordeste e apenas 36\% na Região Sudeste (Brasil. Consea, 2004).

Em Canoinhas-SC, como na maioria dos municípios brasileiros, a alimentação nas escolas da Rede Pública Municipal de Ensino (RPME) é oferecida somente no intervalo do turno escolar, sendo preocupante a condição alimentar dos alunos horas antes desse período. O objetivo deste estudo foi verificar a prevalência de alunos que fazem a refeição no domicílio, antes de se deslocarem à escola, ou a que é oferecida pela escola, bem como identificar os principais fatores associados à omissão da refeição escolar.

\section{Sujeitos do estudo}

Participaram da pesquisa todos os alunos de $1^{\mathrm{a}}$ a $4^{\mathrm{a}}$ série dos turnos matutino e vespertino, matriculados nas 10 escolas da área urbana e nas 12 da área rural pertencentes à RPME de Canoinhas-SC, no ano de 2008. Na área urbana estão localizadas cinco Escolas Básicas Municipais (EBM) e cinco Grupos Escolares Municipais (GEM), e na área rural ficam localizadas outras seis EBM e as seis Escolas Isoladas Municipais (EIM). As EBM atendem alunos de pré-escolar à $8^{a}$ série do ensino fundamental. Os GEM e as EIM só possuem turmas de pré-escolar à $4^{\mathrm{a}}$ série.

Não houve distinção de sexo, etnia, renda familiar ou doença para participar do estudo. Como critérios de exclusão foram considerados os alunos ausentes no dia da entrevista e crianças cujos pais recusaram a participação delas no estudo.

O estudo foi conduzido com o consentimento da Secretaria Municipal de Educação de Canoinhas-SC. Não houve identificação dos participantes, e os dados ficaram armazenados sob responsabilidade do coordenador da pesquisa. O desenvolvimento do estudo seguiu os requisitos da Resolução 196/96 do Conselho Nacional de Saúde, que regulamenta pesquisas envolvendo seres humanos (Brasil. CNS, 2000). O projeto foi aprovado 
pelo Comitê de Ética em Pesquisa da Universidade da Região de Joinville (Univille), sob o Processo nº36/07.

\section{Análise estatística}

Os dados foram analisados utilizando-se o programa Statistical Package for the Social Science (SPSS), versão 16.0. Para avaliar a associação entre as variáveis sexo, série escolar, turno escolar, tipo de escola e área geográfica utilizou-se o teste do Qui-Quadrado, ou teste exato de Fischer, quando necessário. O nível de significância adotado foi $5 \%(p<0,05)$.

\section{Coleta dos dados}

Os dados foram coletados em dois momentos: consumo relatado pelo aluno e consumo verificado na escola.

\section{Consumo relatado pelo aluno}

Tais dados foram coletados mediante entrevista com os alunos, nas escolas, durante o período escolar, em um dia da semana, de segunda a sexta-feira, no período de 18/3/08 a 12/4/2008. As entrevistas foram realizadas em dupla, fora da sala de aula e com duração de aproximadamente 20 minutos por aluno, tendo como objetivo coletar informações sobre o consumo da refeição realizada em dois locais:

- No domicílio do aluno, antes de este se deslocar à escola para o café da manhã ou para o almoço;

- Na escola, durante o intervalo escolar, para registrar informações dos alunos quanto ao consumo dos lanches da manhã e da tarde oferecidos pela escola.

Dados do aluno envolvendo sexo, nome da escola, tipo de escola, série, turno, prevalência de consumo da refeição e motivos de não fazer a refeição na escola e no domicílio também foram coletados nesse momento.

\section{Consumo verificado na escola}

Esta etapa teve como objetivo verificar o consumo dos lanches servidos pela manhã e à tarde na escola, durante o intervalo das aulas, ou seja, registrar o número de alunos que efetivamente consumiram a refeição na escola. Para isto, foram utilizados cartões confeccionados em cinco cores diferentes, correspondentes aos cinco dias letivos da semana. Os cartões foram distribuídos aos alunos pelos professores, na sala de aula, para todas as turmas de $1^{\mathrm{a}}$ a $4^{\mathrm{a}}$ série, e os alunos foram orientados a entregar os cartões no momento da refeição. 
Este procedimento foi realizado nos turnos matutino e vespertino, de segunda a sexta-feira, no mês de abril/2008. Quando uma criança esqueceu o cartão, a cozinheira efetuou a reposição com cartões reserva, exceto nos casos de repetição da refeição, que não foram registrados. Após o intervalo da aula, os cartões foram contados e a frequência foi registrada em formulário específico. Para garantir a veracidade das informações, foram confeccionados oito carimbos, identificados com as turmas de $1^{\text {a }}$ a $4^{\text {a }}$ série e os respectivos turnos, além da sigla da Secretaria Municipal de Educação e identificação do Setor de Alimentação Escolar. Todos os cartões foram carimbados. Após as refeições, os cartões foram contados e o número registrado.

As refeições consumidas na escola seguiram um cardápio elaborado por uma nutricionista responsável pela alimentação escolar das unidades escolares da RPME de Canoinhas-SC. Todos os integrantes do grupo de pesquisa foram capacitados e orientados pela pesquisadora responsável do estudo antes de iniciarem as atividades. Para verificar possíveis erros no instrumento, este foi aplicado em uma turma da $3^{\mathrm{a}}$ e outra da $4^{\mathrm{a}}$ série do turno matutino e em uma turma da $1^{\mathrm{a}}$ e outra da $2^{\mathrm{a}}$ série do turno vespertino, de uma escola da área urbana da rede estadual de ensino, durante uma semana. O mesmo procedimento foi realizado com uma turma de $5^{\mathrm{a}}$ série no turno matutino e outra no turno vespertino em uma escola da área rural da RPME. As escolas e as turmas foram selecionadas aleatoriamente, e o pré-teste foi aplicado no mês de março de 2008. Todos os dados foram coletados pela pesquisadora, auxiliada por duas estagiárias do curso de Nutrição da Unidade de Ensino Superior Vale do Iguaçu (Uniguaçu), de União da Vitória-PR.

\section{Resultados}

Este é o primeiro estudo desenvolvido na cidade de Canoinhas-SC que descreveu o consumo da refeição oferecida pelas escolas da RPME envolvendo turmas de $1^{\mathrm{a}}$ a $4^{\mathrm{a}}$ série das áreas urbana e rural. A principal dificuldade encontrada para o desenvolvimento da pesquisa foi o acesso precário em algumas EIM da área rural. Entretanto, a maciça participação dos alunos $(92,7 \%)$ e dos funcionários das escolas e todo o apoio da Secretaria Municipal de Educação foram características que influenciaram positivamente na coleta dos dados.

Dos 2.678 alunos matriculados nas 22 escolas da RPME de Canoinhas-SC, em turmas de $1^{\mathrm{a}}$ a $4^{\mathrm{a}}$ série dos turnos matutino e vespertino, 195 não participaram do estudo, por não estarem presentes na escola no dia da entrevista. Desta forma, $2.483(92,7 \%)$ foram entrevistados para a obtenção do relato de consumo da refeição no domicílio e na escola, sendo $1.583(63,8 \%)$ alunos pertencentes a escolas da área urbana e 900 $(36,2 \%)$ a escolas da área rural. O sexo masculino foi o mais prevalente $(53,6 \%)$ e o turno vespertino, o mais frequentado (61,3\%).

Na Tabela 1 são descritos o consumo relatado da refeição no domicílio antes de o aluno se deslocar à escola e o da refeição oferecida pela escola, 
segundo variáveis sociodemográficas. O teste do Qui-quadrado para proporcionalidade mostrou que as variáveis sexo, série escolar, turno escolar e tipo de escola apresentaram diferença significativa para consumo do café da manhã e almoço no domicílio antes do aluno se deslocar à escola, ao contrário da variável área geográfica.

As meninas foram as que mais declararam não consumir a refeição no domicílio antes de se deslocarem à escola. Esse comportamento também foi observado quanto ao consumo da refeição oferecida na escola, porém de forma menos expressiva $(p>0,05)$. Acredita-se que esta conduta observada no sexo feminino possa estar associada ao fato de ser cada vez mais precoce a preocupação com a aparência, resultando na visão distorcida que a menina faz diante dos alimentos. Pesquisas apontam a presença deste comportamento entre jovens, principalmente nas meninas. Os transtornos alimentares, como anorexia nervosa e bulimia, que iniciam na adolescência, vêm apresentando crescente incidência nas últimas décadas e têm sido identificados em diferentes culturas e classes sociais (Fleitlich, Larino, Cordás, 2000).

Tabela 1 - Consumo Relatado da Refeição no Domicílio, antes de o Aluno se Deslocar à Escola, e da Refeição Oferecida pela Escola, segundo Variáveis Sociodemográficas - Canoinhas-SC - 2008

\begin{tabular}{|c|c|c|c|c|c|c|c|c|c|c|}
\hline \multirow{3}{*}{ Variável } & \multicolumn{4}{|c|}{$\begin{array}{l}\text { Consumida no domicílio } \\
\qquad(n=2.483)\end{array}$} & \multirow{3}{*}{$\mathbf{p}$} & \multicolumn{4}{|c|}{$\begin{array}{l}\text { Oferecida pela escola } \\
\qquad(n=2.483)\end{array}$} & \multirow{3}{*}{$\mathbf{p}$} \\
\hline & \multicolumn{2}{|c|}{$\begin{array}{c}\text { Sim } \\
(n=2.260)\end{array}$} & \multicolumn{2}{|c|}{$\begin{array}{c}\text { Não } \\
(n=223)\end{array}$} & & \multicolumn{2}{|c|}{$\begin{array}{c}\text { Sim } \\
(n=2.375)\end{array}$} & \multicolumn{2}{|c|}{$\begin{array}{c}\text { Não } \\
(n=108)\end{array}$} & \\
\hline & $\mathbf{N}$ & $\%$ & $\mathbf{N}$ & $\%$ & & $\mathbf{N}$ & $\%$ & $\mathbf{N}$ & $\%$ & \\
\hline Sexo & & & & & 0,004 & & & & & 0,119 \\
\hline Masculino & 1.232 & 92,6 & 99 & 7,4 & & 1.281 & 96,2 & 50 & 3,8 & \\
\hline Feminino & 1.028 & 89,0 & 124 & 11,0 & & 1.094 & 95,0 & 58 & 5,0 & \\
\hline Série escolar & & & & & 0,000 & & & & & 0,912 \\
\hline Primeira & 499 & 94,7 & 28 & 5,3 & & 507 & 96,2 & 20 & 3,8 & \\
\hline Segunda & 628 & 92,2 & 53 & 7,8 & & 650 & 95,4 & 31 & 4,6 & \\
\hline Terceira & 623 & 90,9 & 62 & 9,1 & & 655 & 95,6 & 30 & 4,4 & \\
\hline Quarta & 510 & 86,4 & 80 & 13,6 & & 563 & 95,4 & 27 & 4,6 & \\
\hline Turno escolar & & & & & 0,000 & & & & & 0,710 \\
\hline Matutino & 810 & 84,2 & 152 & 15,8 & & 922 & 95,8 & 40 & 4,2 & \\
\hline Vespertino & 1.450 & 95,3 & 71 & 4,7 & & 1.453 & 95,5 & 68 & 4,5 & \\
\hline Tipo de escola $\left({ }^{*}\right)$ & & & & & 0,006 & & & & & 0,000 \\
\hline EBM & 1.627 & 91,3 & 155 & 8,7 & & 1.686 & 94,6 & 96 & 5,4 & \\
\hline GEM & 508 & 92,0 & 44 & 8,0 & & 540 & 97,8 & 12 & 2,2 & \\
\hline EIM & 125 & 83,9 & 24 & 16,1 & & 149 & 100 & 0 & 0,0 & \\
\hline Área geográfica & & & & & 0,679 & & & & & 0,002 \\
\hline Urbana & 1.438 & 90,8 & 145 & 9,2 & & 1.499 & 94,7 & 84 & 5,3 & \\
\hline Rural & 822 & 91,3 & 78 & 8,7 & & 876 & 97,3 & 24 & 2,7 & \\
\hline
\end{tabular}

(*) EBM: Escola Básica Municipal; GEM: Grupo Escolar Municipal; EIM: Escola Isolada Municipal. 
Quando investigados em relação ao consumo da refeição no domicílio (café da manhã, turno matutino; almoço, turno vespertino), a maioria $(91,0 \%)$ declarou realizar a refeição em casa, antes de ir à escola. Apesar de 9,0\% dos alunos terem relatado não consumir a refeição no domicílio antes de se deslocarem à escola, esse valor foi inferior ao verificado por outros pesquisadores, como Pedraza et al. (2007), que registraram 14,2\% em Olinda-PE, Sturion et al. (2003), que apontou 14,6\% em um estudo realizado com uma amostra de 10 municípios brasileiros, e Gambardella, Frutuoso e Franchi (1999), que observaram a prática de não realizar o desjejum em mais de 50\% dos adolescentes no município de Santo André-SP. Wolfe e Campbell (1993), em um estudo realizado no Estado de New York, USA, também encontraram valores similares aos do Brasil, de $16 \%$. A mudança no estilo de vida das crianças nos últimos 25 anos, principalmente em relação aos hábitos alimentares, pode ser atribuída às alterações no ambiente familiar e social de maneira geral (Fernández San Juan, 2006). Incentivar os filhos a terem uma alimentação equilibrada durante o dia é dever dos pais, principalmente para as crianças em idade escolar, pois, nesse período, as crianças costumam incorporar hábitos alimentares de outras pessoas. Neste sentido, é fundamental que as principais refeições do dia sejam realizadas em família.

Quanto à série escolar, percebeu-se que há uma diminuição do consumo da refeição no domicílio, café da manhã para o turno matutino e almoço para o turno vespertino, com o avanço da série escolar. Este fato pode estar relacionado à maior dedicação e atenção dos pais com a alimentação das crianças de menor idade, aliada à liberdade da criança em escolher os alimentos à medida que vai crescendo e, consequentemente, criando suas preferências. Muitas vezes os pais não interferem nos hábitos alimentares das crianças, e estas passam a consumir alimentos fora de casa com maior frequência, comprometendo a qualidade dessas refeições.

Como esperado e corroborando outros estudos, a maior prevalência de omissão da refeição no domicílio foi encontrada no turno matutino, ou seja, 15,8\% dos alunos deslocaram-se à escola sem tomar o café da manhã. A omissão do café da manhã pelos escolares vem sendo discutida há décadas. Um estudo realizado por Rosenburg (1977) verificou que $12,6 \%$ das crianças vão à escola em completo jejum. Wolfe e Campbell (1993) identificaram que 16,0\% dos alunos não consumiam o café da manhã e Gambardella, Frutuoso e Franch (1999) observaram a prática de não realizar o desjejum padrão em mais de 50,0\% dos adolescentes estudados.

O café da manhã, ou desjejum, é considerado uma das principais refeições do dia, e omitir essa refeição pode ser prejudicial ao desempenho acadêmico dos alunos ao longo dos anos. Em um inquérito populacional realizado em Campinas-SP, com 456 famílias, para avaliar o consumo diário de alimentos de famílias em situação de insegurança alimentar, as 
famílias classificadas com insegurança alimentar moderada ou grave eram justamente as que não faziam uma das três principais refeições diárias. O resultado do estudo mostrou que 19,6\% das famílias não consumiam o café da manhã, 11,2\% não almoçavam e 13,2\% não jantavam (Panigassi et al., 2008).

Nesse estudo, os dados também revelaram que 4,7\% dos alunos matriculados no turno vespertino declararam não almoçar antes de ir à escola. A princípio parece pouco, mas, quando se trata de almoço, tal resultado toma outra dimensão. Como o almoço é frequentemente considerado a principal refeição do dia para a maioria das pessoas, este é um fato preocupante, já que aponta para a realidade de algumas crianças brasileiras, as quais utilizam a refeição servida na escola como sendo a principal e única refeição garantida do dia (Bezerra, 2009).

O tipo de escola também mostrou ser um fator que influencia o consumo da refeição no domicílio, sobretudo nas EIM, onde 16,1\% dos alunos declararam não consumir a refeição no domicílio antes de irem à escola. Acredita-se que este resultado seja devido ao fato de, para esses alunos, a merenda escolar ser considerada a principal refeição do dia, já que vivem em áreas isoladas. Entretanto, não foi questionado no presente estudo o interesse da criança em ir à escola apenas por causa da merenda escolar. Todavia, Muniz e Carvalho (2007) observaram que 0,9\% de crianças do município de João Pessoa, Paraíba, frequentavam a escola em busca da merenda escolar. Esta questão foi reafirmada ao abordar as consequências do não oferecimento da merenda escolar, quando, apesar de $37,8 \%$ responderem que a supressão da merenda seria negativa, e atribuírem esta condição, sobretudo, à necessidade financeira de seus pais, apenas 4,4\% referiram que deixariam de ir à escola caso o Pnae fosse extinto (Muniz, Carvalho, 2007).

Acredita-se que, mesmo não havendo diferença significativa para consumo da refeição no domicílio em relação à área geográfica, as crianças que residem na área rural tendem a consumir tal refeição com maior frequência ao longo da semana devido à presença constante da família, exceto em épocas de intensificação do trabalho agrícola. Em geral, na área rural, o hábito de efetuar as refeições em família é muito comum, o que dificulta a omissão de qualquer refeição por parte da criança.

\section{Refeição oferecida pela escola}

Quando investigados em relação ao consumo da refeição oferecida pela escola, 95,7\% dos alunos afirmaram consumi-la (Tabela 1). Tal resultado é expressivo, quando comparado a outros estudos, com prevalências variando de $65,5 \%$ a $90,8 \%$ para o consumo da alimentação oferecida pela escola (Flávio, Barcelos, Lima, 2004; Martins et al., 2004; Muniz, Carvalho, 2007; Maestro, 2002; Danelon, Danelon, Silva, 2006; Mielniczuk, 2005; Carvalho, 2005). Acredita-se que um dos fatores responsáveis pela elevada prevalência do consumo da refeição oferecida 
pelas escolas no município de Canoinhas seja o reduzido número de escolas com cantinas, limitando-se a ocorrência somente a uma EBM da área rural. Em contrapartida, das 22 escolas investigadas, 10 possuíam venda de lanches: cinco em escolas da área urbana e cinco em escolas da área rural. Como a venda de lanches é um procedimento esporádico nas escolas, supõe-se que essa característica ainda não esteja influenciando a escolha do aluno em consumir a refeição oferecida pela escola.

Alguns estudos têm apontado que, além de grande parte dos alunos gostarem da alimentação servida na escola (Martins et al., 2004), tal refeição torna-se importante também devido à dificuldade financeira encontrada em várias famílias (Muniz, Carvalho, 2007). Este é um fator relevante, na medida em que muitas famílias contam com essa possibilidade oferecida pela escola para garantir uma alimentação adequada aos seus filhos. Além disso, o ambiente escolar é um importante local para a formação de bons hábitos alimentares e para a educação nutricional. Nesse contexto, destacam-se os serviços de alimentação presentes nas escolas, como o Pnae e as cantinas (Danelon, Danelon, Silva, 2006).

No ambiente escolar também devem ser desenvolvidas atividades de educação nutricional para pais e alunos, com orientações sobre a importância da alimentação diária adequada em quantidade e qualidade, contribuindo para melhorar os hábitos alimentares da família. Meyers et al. (1989), em estudo desenvolvido com uma comunidade pobre, verificaram que crianças que receberam o café da manhã na escola melhoraram significativamente suas notas em relação àquelas que não receberam o café da manhã. A refeição oferecida pela escola antes das atividades escolares e/ou durante o intervalo das aulas deve contribuir para atingir as necessidades nutricionais diárias das crianças em idade escolar (Brasil. FNDE, 2006). Worobey e Worobey (1999), em um estudo que analisou a eficácia de um programa de lanche na pré-escola, demonstraram que houve melhora no padrão nutricional de estudantes que consumiram o café da manhã na escola. Gabriel, Santos e Vasconcellos (2008) revelaram aumento de 15\% no consumo da refeição oferecida pela escola após intervenção nutricional.

No município de Canoinhas-SC, cidade onde este estudo foi realizado, a oferta da alimentação escolar gratuita ocorre em 100\% das escolas da RPME, de acordo com o preconizado pelo Pnae. Deste modo, todas as crianças matriculadas nas 22 escolas da rede de ensino têm acesso à alimentação escolar durante os 200 dias letivos do ano. De forma a melhorar a qualidade da alimentação oferecida nas escolas, é fundamental conhecer o número de alunos que efetivamente consomem a alimentação escolar, assim como os fatores que levam os alunos a não consumirem a refeição da escola.

No relato do consumo da refeição oferecida pela escola, ao contrário do encontrado para consumo da refeição no domicílio, a variável área geográfica foi um fator significativo para os alunos consumirem a refeição, corroborando o comentado anteriormente, onde há menor prevalência 
$(2,7 \%)$ em não consumir a refeição oferecida pela escola a crianças pertencentes a famílias da área rural. Percebe-se aqui a importância da alimentação oferecida pela escola para crianças da área rural, visto que, além da alimentação consumida na residência, a maioria das crianças ainda consome essa modalidade de refeição.

Assim como a área geográfica, a variável tipo de escola também apresentou diferença significativa em relação ao consumo da alimentação oferecida pela escola. Ainda que o percentual de consumo seja elevado $(94,6 \%)$, os alunos pertencentes às EBM foram os que menos relataram consumir a refeição oferecida pela escola quando comparados aos alunos dos GEM e das EIM.

O Gráfico 1 representa os principais motivos relatados pelos alunos que não consumiram a refeição oferecida pela escola. Conforme constatamos, entre os principais motivos relatados pelos alunos em relação a não consumirem a refeição oferecida pela escola, destacam-se o fato de os alunos trazerem lanche de casa e o hábito de não efetuarem a refeição no intervalo das aulas, vindo de encontro ao relatado por outros estudos (Muniz, Carvalho, 2007; Martins et al., 2004; Flávio, Barcelos, Lima, 2004). Em seu estudo, Muniz e Carvalho (2007) verificaram que, mesmo consumindo o lanche oferecido pela escola, muitos alunos ainda trazem alimentos de casa e os compram na escola. Nesse mesmo estudo, entre os principais motivos relatados pelos alunos para não consumirem o alimento na escola, foram mencionados a inadequação das preparações aos seus hábitos alimentares, o fato de trazerem lanche de casa, por estarem sem apetite e, também, devido à preparação do dia não estar saborosa (Muniz, Carvalho, 2007). Resultados semelhantes também foram descritos por outros pesquisadores (Martins et al., 2004; Claudino, 2006; Flávio, Barcelos, Lima, 2004).

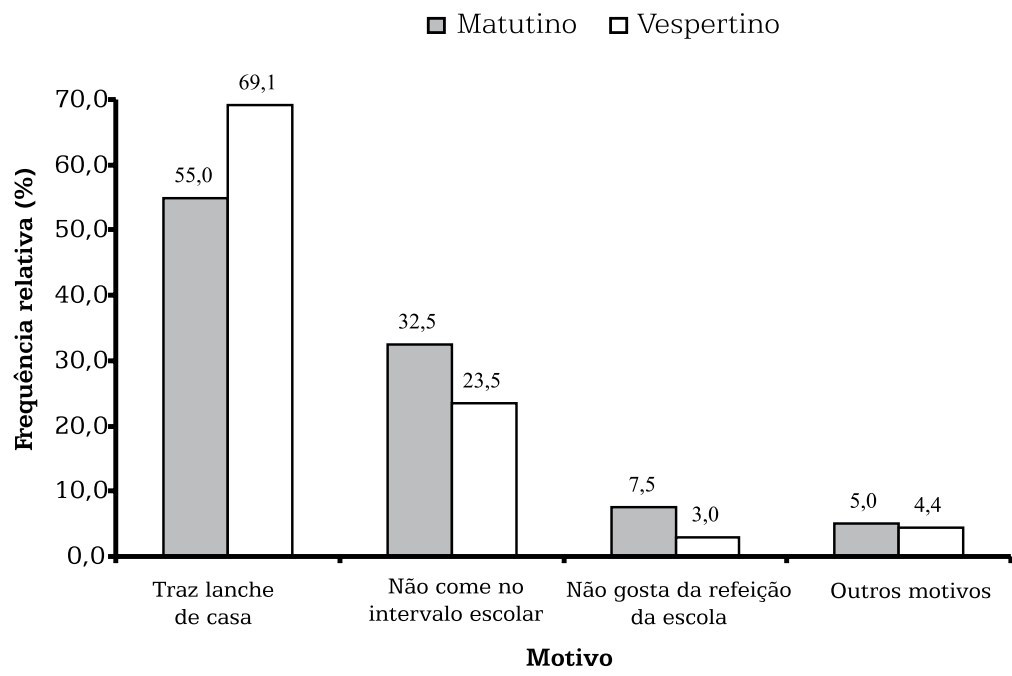

Gráfico 1 - Motivos Relatados por 108 Alunos que os Levaram a não Consumir a Refeição Oferecida pela Escola. Canoinhas-SC, 2008. 
Os motivos "traz lanche de casa" e "não come no intervalo escolar", relatados pelos alunos durante a entrevista, podem estar relacionados a fatores como: desconhecimento dos pais da qualidade da refeição oferecida pela escola; cardápio repetitivo; demora no servimento da refeição, que muitas vezes leva o aluno a optar entre fazer a refeição ou brincar e, ainda, a concepção de que a alimentação escolar é fornecida somente a crianças carentes. Cabe lembrar que a população de Canoinhas ainda é predominantemente germânica, e trazer lanche de casa ainda é um hábito comum entre as famílias, até porque também está associado ao gosto do alimento. Muitos alunos, sobretudo os das primeiras séries, possivelmente ainda não se acostumaram com o lanche oferecido pela escola, e preferem trazer o de casa.

Em relação à frequência de consumo da refeição oferecida pela escola ao longo da semana, apresentada no Gráfico 2, a maioria dos alunos declarou no presente estudo consumi-la todos os dias, independentemente do turno. Novamente, atribui-se esse resultado à ausência de cantinas na maioria das escolas estudadas. Sabe-se que a venda de salgadinhos, refrigerantes e outras guloseimas em cantinas e lanchonetes dentro das escolas ou próximo a elas está relacionada à baixa adesão à alimentação escolar (Martins et al., 2004). Outro fator que pode estar relacionado à elevada adesão da refeição oferecida pela escola diz respeito ao fato de o estudo ter envolvido apenas alunos de $1^{\mathrm{a}}$ a $4^{\mathrm{a}}$ série.

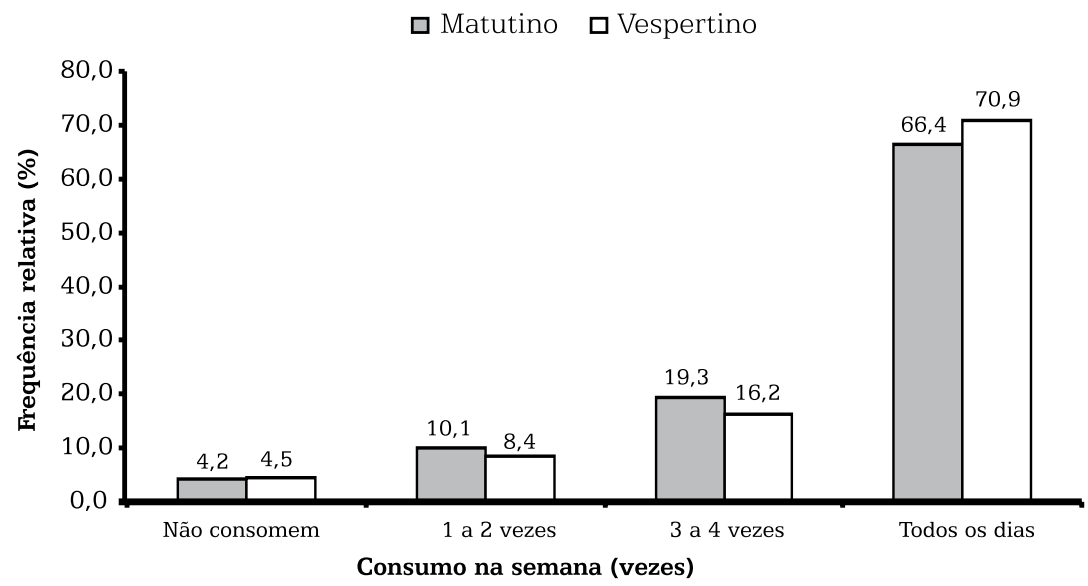

\section{Gráfico 2 - Consumo relatado do lanche oferecido pela escola ao longo da semana. Canoinhas-SC, 2008.}

Alguns estudos têm demonstrado que a adesão à refeição oferecida pela escola é maior no caso de alunos menores de 12 anos de idade, chegando em torno de quatro vezes por semana (Silva et al. 2002; Claudino, 2006). Em vários estudos realizados em outros municípios brasileiros, as frequências diárias de consumo das refeições oferecidas pela escola foram inferiores às observadas no presente estudo (Flávio, Barcelos, Lima, 2004; Carvalho, 2005; Claudino, 2006; Danelon, Danelon, 
Silva, 2006; Muniz, Carvalho, 2007; Sturion et al., 2005; Oliveira, 1997; Pedraza et al., 2007; Brasil. MEC, 2002).

\section{Consumo registrado da refeição oferecida pela escola}

Quando se investigou o número de refeições efetivamente consumidas pelos alunos e oferecidas pela escola no intervalo escolar, uma EIM da área rural foi excluída do estudo, devido às condições climáticas e dificuldades de acesso. Desta forma, nas 21 escolas investigadas, 46.942 refeições foram oferecidas a todos os alunos no intervalo escolar, entretanto, 36.287 $(77,3 \%)$ refeições foram efetivamente consumidas. Das 10.655 (22,7\%) refeições não consumidas pelos alunos no intervalo escolar, considerando o número de alunos presentes em sala de aula, a maior prevalência foi encontrada em turmas de $1^{\text {a }}$ série $(23,8 \%)$, pertencentes ao turno vespertino (24,2\%), de EBM (26,2\%), da área urbana (26,7\%) e em dias em que o cardápio oferecido foi de preparação salgada (24,0\%). Todas as variáveis investigadas mostraram-se associadas de forma significativa com o consumo da refeição na escola; ou seja, série escolar, turno escolar, tipo de escola, área geográfica e tipo de cardápio são fatores importantes a serem considerados para o consumo da refeição na escola (Tabela 2).

Além dos fatores já descritos, vários outros podem ser considerados para justificar o elevado número de refeições não consumidas, como a preferência para brincar no intervalo escolar, talvez o fato de não gostarem do lanche oferecido pela escola e, principalmente, devido ao hábito de muitos ainda trazerem o lanche de casa.

Sturion et al. (2005) verificaram que o consumo da alimentação escolar e o número de refeições que o aluno recebe em casa estão negativamente correlacionados. Segundo os autores, dos alunos que fizeram até três refeições no domicílio, 56,3\% consumiram a refeição escolar de quatro a cinco vezes por semana. Entre os que informaram ter realizado três ou mais refeições por dia no domicílio, apenas 51,9\% a consumiram na mesma frequência. Portanto, valores superiores de consumo da alimentação escolar foram observados em alunos que realizaram até três refeições no domicílio.

Quando investigados em relação ao tipo de refeição oferecida, houve preferência para o consumo de alimentos doces (79,0\%). Resultado semelhante foi descrito por Claudino (2006), que enfatizou a preferência dos cereais e dos biscoitos com leite em detrimento da preparação salgada como arroz e feijão, saladas, legumes e frutas em geral. Segundo o autor, esta preferência pode estar associada ao horário em que as refeições foram servidas, as quais são oferecidas nos intervalos da manhã e da tarde. De qualquer forma, esse não parece ser um comportamento padrão, já que outros pesquisadores descreveram resultados divergentes, com maior consumo de preparações salgadas (Faria et al., 2004). 
Tabela 2 - Consumo Registrado da Refeição Oferecida pela Escola, segundo Variáveis Sociodemográficas e Cardápio. Canoinhas-SC, 2008

\begin{tabular}{|c|c|c|c|c|c|c|c|}
\hline \multirow{3}{*}{ Variável } & \multicolumn{6}{|c|}{ Consumiram a refeição oferecida pela escola } & \multirow{3}{*}{$\mathbf{p}$} \\
\hline & \multicolumn{2}{|c|}{$\operatorname{Sim}(n=36.287)$} & \multicolumn{2}{|c|}{ Não $(n=10.655)$} & \multicolumn{2}{|c|}{ Total $(n=46.942)$} & \\
\hline & $\mathbf{n}$ & $\%$ & $\mathbf{n}$ & $\%$ & $\mathbf{n}$ & $\%$ & \\
\hline \multicolumn{7}{|l|}{ Série escolar } & \multirow{5}{*}{0,011} \\
\hline Primeira & 7.583 & 76,2 & 2.371 & 23,8 & 9.954 & 100 & \\
\hline Segunda & 10.049 & 78,0 & 2.828 & 22,0 & 12.877 & 100 & \\
\hline Terceira & 10.152 & 77,4 & 2.960 & 22,6 & 13.112 & 100 & \\
\hline Quarta & 8.503 & 77,3 & 2.496 & 22,7 & 10.999 & 100 & \\
\hline \multicolumn{7}{|l|}{ Turno escolar } & \multirow{3}{*}{0,000} \\
\hline Matutino & 14.696 & 79,6 & 3.763 & 20,4 & 18.459 & 100 & \\
\hline Vespertino & 21.591 & 75,8 & 6.892 & 24,2 & 28.483 & 100 & \\
\hline \multicolumn{7}{|l|}{ Tipo de escola $\left({ }^{*}\right)$} & \multirow{4}{*}{0,000} \\
\hline EBM $(1-8)$ & 24.527 & 73,8 & 8.686 & 26,2 & 33.213 & 100 & \\
\hline GEM $(1-4)$ & 9.120 & 83,6 & 1.784 & 16,4 & 10.904 & 100 & \\
\hline EIM (Multiseriada) & 2.640 & 93,5 & 185 & 6,5 & 2.825 & 100 & \\
\hline \multicolumn{7}{|l|}{ Área geográfica } & \multirow{3}{*}{0,000} \\
\hline Urbana & 22.001 & 73,3 & 8.017 & 26,7 & 30.018 & 100 & \\
\hline Rural & 14.286 & 84,4 & 2.638 & 15,6 & 16.924 & 100 & \\
\hline Cardápio & & & & & & & 0,000 \\
\hline Doce & 16.533 & 79,0 & 4.408 & 21,0 & 20.941 & 100 & \\
\hline Salgado & 19.754 & 76,0 & 6.247 & 24,0 & 26.001 & 100 & \\
\hline
\end{tabular}

(*) EBM: Escola Básica Municipal; GEM: Grupo Escolar Municipal; EIM: Escola Isolada Municipal.

\section{Considerações finais}

Apesar dos resultados obtidos no presente estudo terem sido melhores do que outros em relação ao consumo da refeição no domicílio, antes de os alunos se deslocarem à escola, torna-se fundamental a orientação de pais e alunos sobre a importância de realizar as refeições diárias adequadamente em quantidade e qualidade no domicílio. Tal ênfase deve ser direcionada à primeira refeição do dia, visto que foi a refeição mais omitida pelos escolares do turno matutino. Este também é um assunto que deve ser elaborado nas escolas, envolvendo os pais e solicitando que estes se envolvam mais diretamente na alimentação dos seus filhos. Identificar os motivos que levam o aluno a não consumir a refeição tanto no domicílio como na escola torna-se fundamental para garantir a manutenção de sua qualidade de vida, já que a alimentação inadequada ou insuficiente acarreta problemas no desenvolvimento da criança e a consequente perda do rendimento escolar. 


\section{Referências bibliográficas}

BEZERRA, José Arimatea Barros. Alimentação e escola: significados e implicações curriculares da merenda escolar. Revista Brasileira de Educação, Rio de Janeiro, v. 14, n. 40, p. 103-115, 2009.

BRASIL. Conselho Nacional de Saúde (CNS). Comissão Nacional de Ética em Pesquisa. Normas para pesquisa envolvendo seres humanos (Res. CNS 196/96 e outras). Brasília: MS-CNS-Conep, 2000. p. 5-87. (Série Cadernos Técnicos).

BRASIL. Conselho Nacional de Segurança Alimentar e Nutricional (Consea). Princípios e diretrizes de uma Política de Segurança Alimentar e Nutricional. Brasília: Positiva, 2004. 80 p.

BRASIL. Fundo Nacional de Desenvolvimento da Educação (FNDE). Conselho Deliberativo. Resolução FNDE CD no 032, de 10 de agosto de 2006. Estabelece as normas para a execução do Programa Nacional de Alimentação Escolar (Pnae). 2006. Disponível em: <http://www.fnde.gov.br>. Acesso em: 10 jan. 2009.

BRASIL. Ministério da Educação e do Desporto (MEC). Avaliação do impacto distributivo e elaboração de sistemática de monitoramento do Pnae [relatório final de pesquisa]. Brasília, 2002.

CARVALHO, L. M. F. Preferências alimentares de crianças e adolescentes matriculados no ensino fundamental da rede pública da cidade de Bauru: uma análise de fatores ambientais no estudo da obesidade. 2005. Dissertação (Mestrado) - Universidade de São Paulo, Ribeirão Preto, 2005.

CLAUDINO, M. A. F. Políticas públicas de alimentação escolar: uma análise com enfoque no município de São José dos Campos-SP. 2006. Dissertação (Mestrado) - Universidade São Marcos, São Paulo, 2006.

DANELON, Maria Angélica Schievano; DANELON, Mariana Schievano; SILVA, Marina Vieira. Serviços de alimentação destinados ao público escolar: análise da convivência do Programa de Alimentação Escolar e das cantinas. Segurança Alimentar e Nutricional, Campinas, v. 1, n. 13, p. 85-94, 2006.

FARIA, A. L. C. et al. Avaliação antropométrica e educação nutricional de escolares de $1^{\mathrm{a}}$ a $4^{\mathrm{a}}$ série de uma escola estadual do município de Araraquara. Revista Uniara, Araraquara, v.15, p. 189-200, 2004. 
FERNÁNDEZ SAN JUAN, Pedro Mario. Dietary habits and nutritional status of school aged children in Spain. Nutrición Hospitalaria, Madrid, v. 21, n. 3, p. 374-378, 2006.

FLÁVIO, E. F.; BARCELOS, M. F. P.; LIMA, A. L. Avaliação química e aceitação da merenda escolar de uma escola estadual de Lavras-MG. Ciência e Agrotecnologia, Lavras, v. 28, n. 4, p. 840-847, 2004.

FLEITLICH, Bacy W.; LARINO, Maria A.; CORDÁS, Táki A. Anorexia nervosa na adolescência. Jornal de Pediatria, Rio de Janeiro, v. 76, Supl. 3, p. s323-s329, 2000.

GABRIEL, Cristine Garcia; SANTOS, Melina Valério; VASCONCELLOS, Francisco de Assis Guedes. Avaliação de um programa para promoção de hábitos alimentares saudáveis em escolares de Florianópolis, Santa Catarina, Brasil. Revista Brasileira de Saúde Materno Infantil, Recife, v. 8, n. 3, p. 299-308, 2008.

GAMBARDELLA, Ana Maria Dianezi; FRUTUOSO, Maria Fernanda Petroli; FRANCH, Claudia. Prática alimentar de adolescentes. Revista de Nutrição, Campinas, v. 12, n. 1, p. 5-19, 1999.

MAESTRO, V. Padrão alimentar e estado nutricional: caracterização de escolares de Município Paulista. 2002. Dissertação (Mestrado) Universidade de São Paulo, Piracicaba, 2002.

MARTINS, R. C. B. et al. Aceitabilidade da alimentação escolar no ensino público fundamental. Saúde em Revista, Piracicaba, v. 6, n. 13, p. 71-78, maio/ago. 2004.

MEYERS, A. F. et al. School breakfast program and school performance. American Journal of Diseases of Children, n. 143, p. 1234-1239, 1989.

MIELNICZUK, V. B. O. Gosto ou necessidade? Os significados da alimentação escolar no município do Rio de Janeiro. 2005. Dissertação (Mestrado) - Universidade Federal Rural do Rio de Janeiro, Rio de Janeiro, 2005.

MOYSÉS, Maria Aparecida A.; LIMA, Gerson Z. Fracasso escolar, um fenômeno complexo: desnutrição, apenas mais um fator. Pediatria, São Paulo, v. 5, n. 4, p. 263-269, 1983.

MUNIZ, Vanessa Messias; CARVALHO, Alice Teles. O Programa Nacional de Alimentação Escolar em município do Estado da Paraíba: um estudo sob o olhar dos beneficiários do Programa. Revista de Nutrição, Campinas, v. 3, n. 20, p. 285-296, 2007. 
OLIVEIRA, J. O papel da merenda na alimentação diária dos ingressantes no primeiro grau das escolas municipais de São Paulo. 1997. Dissertação (Mestrado) - Universidade de São Paulo, São Paulo, 1997.

OLIVEIRA, José Eduardo Dutra. Educação e direito à alimentação. Estudos Avançados, São Paulo, v. 21, n. 60, p. 127-134, 2007.

PANIGASSI, G. et al. Insegurança alimentar intrafamiliar e perfil de consumo de alimentos. Revista de Nutrição, v. 21 (Suplemento), p. 135$144,2008$.

PEDRAZA, D. F. et al. Avaliação do Programa de Alimentação Escolar Municipal de Olinda-Pernambuco. Revista Brasileira em Promoção da Saúde, Fortaleza, v. 20, n. 2, p. 76-85, 2007.

POLLITT, Ernesto; GERSOVITZ, Mitchell; GARGIULO, Marita. Educational benefits of the United States school feeding program: a critical review of the literature. American Journal of Public Health, n. 68, p. 477-481, 1978.

ROSENBURG, Ondina. O desjejum dos alunos das quatro primeiras séries de nível I das escolas da Rede Municipal de Ensino de São Paulo, SP - Brasil. Revista de Saúde Pública, São Paulo, n. 11, p. 465-479, 1977.

SILVA, M. V. et al. Estado nutricional de escolares e seu acesso a programas sociais em dez municípios brasileiros. Nutrire, São Paulo, v. 23, p. 33-53, 2002.

STURION, G. L. et al. Fatores condicionantes da adesão dos alunos ao Programa de Alimentação Escolar no Brasil. Revista de Nutrição, Campinas, v. 18, n. 2, p. 167-181, mar./abr. 2005.

WOLFE, Wendy S.; CAMPBELL, Cathy C. Food pattern, diet quality, and related characteristics of schoolchildren in New York State. Journal of the American Dietetic Association, New York, v. 93, n. 11, p. 12801284, Nov. 1993.

WOROBEY, Harriet S.; WOROBEY, John. Efficacy of a preschool breakfast program in reducing refined sugar intake. International Journal of Food Science Nutrition, Basingstoke, v. 50, n. 6, p. 391-397, 1999. 
Cristiane Herbst Mota, mestre em Saúde e Meio Ambiente pela Universidade da Região de Joinville (Univille), é responsável técnica pelo Programa Nacional de Alimentação Escolar das Unidades da Rede Municipal de Ensino de Canoinhas-SC.

cris.herbst@terra.com.br

Silmara Salete de Barros Silva Mastroeni, doutora em Saúde Pública pela Universidade de São Paulo (USP), é docente do Departamento de Educação Física da Universidade da Região de Joinville (Univille) e docente do curso de Nutrição da Associação Luterana Bom Jesus.

silmaramastroeni@yahoo.com.br

Marco Fabio Mastroeni, doutor em Saúde Pública pela Universidade de São Paulo (USP), é docente do Programa de Mestrado em Saúde e Meio Ambiente da Universidade da Região de Joinville (Univille).

marco.mastroeni@gmail.com

Recebido em 20 de maio de 2012.

Aprovado em 7 de novembro de 2012. 